\title{
Aspects of calculating the temperature for the graphite stack of the RBMK reactor
}

\author{
Alexander Vorobiev ${ }^{1, *}$, and Alexandra Antonova ${ }^{1}$ \\ ${ }^{1}$ National Research Tomsk Polytechnic University, 634050 Tomsk, Russia
}

\begin{abstract}
The effect of thermal contact resistance in the elements of the graphite stack of the RBMK reactor on moderator temperature is studied. It is shown that estimation of the thermal contact resistance improves the accuracy of calculation of the graphite moderator temperature.
\end{abstract}

\section{Introduction}

One of the factors that determine the operational reliability and safety of nuclear power plants with water-graphite reactors is the reliability of the graphite moderator (stack) designed for the entire period of the reactor operation.

The graphite stack of the RBMK-1000 reactor has the shape of a cylinder with a diameter of $11.8 \mathrm{~m}$ and a height of $7 \mathrm{~m}$ made up of 2488 columns. The columns have vertical holes with pipes arranged inside as fuel channels (FC) and CPS channels. Fuel assemblies inside the channels are cooled by water with a temperature of $250 \ldots 280^{\circ} \mathrm{C}$ [1].

During operation of the reactor, a portion $(5 \ldots 6 \%)$ of its total thermal power is released in the graphite stack. This heat is also removed to the FC tubes. To ensure the thermal contact with blocks, the tubes are encircled with split graphite rings (Fig. 1), and the sweep gas is supplied through the gaps between the tubes and blocks (reference composition of $10 \%$ nitrogen and $90 \%$ helium, by volume) $[1,2]$.

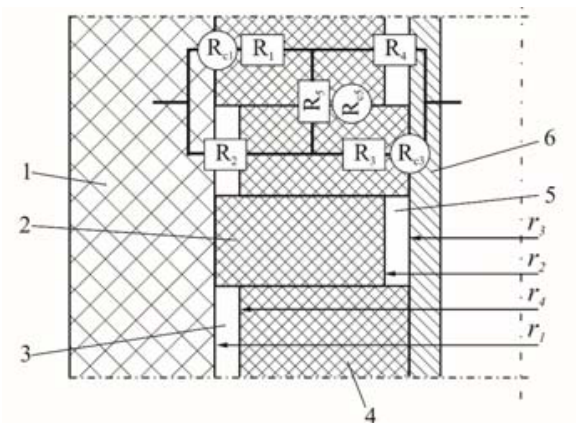

Fig. 1. Schematic diagram of FC tube arrangement in a graphite stack: graphite block (1); outer graphite ring (2); gas gaps $(3,5)$; inner graphite ring (4); $R_{i}$ is thermal resistance; $R_{c i}$ is contact

* Corresponding author: worob@tpu.ru 
thermal resistance; $r_{i}$ is radius.

The design and schematics of the RBMK reactor plant make possible to change the composition of the sweep gas [1].

The temperature field in the graphite stack primarily depends on the reactor power. The nitrogen content in the nitrogen-helium mixture (hereinafter, the sweep gas composition) affects the graphite temperature as well.

The graphite stack temperature is one of the main parameters that limit the RBMK reactor operation. In practice, it is assumed that the maximum graphite temperature should not exceed the threshold temperature of $750 \ldots 800{ }^{\circ} \mathrm{C}$ in all operational conditions of the reactor [2, 3]. In addition, variations in the average temperature of the graphite stack (moderator) cause changes in the reactor reactivity, as the RBMK units have a positive effect on reactivity relative to the moderator temperature $[1,3]$.

Consequently, estimation of the temperature of the RBMK graphite stack is a crucial task.

\section{Calculation technique}

The temperature field of the water-graphite reactor stack is three-dimensional. The programs for numerical calculations of two-dimensional and three-dimensional temperature field are very complex. Therefore, various simplifications and assumptions should be performed to estimate the maximum temperature of graphite $[4,5]$.

In the known method of calculating the maximum temperature of the RBMK reactor moderator [6], thermal resistances of bearings and gas gaps act like electrical resistances. The circuit of resistances being made and simplified, an equivalent electric and hence thermal resistance of the gap graphite block-fuel channel tube can be evaluated (Fig. 1).

\section{Calculation results}

The results of variants calculations of the temperature of an individual graphite block obtained by the considered technique are shown in Fig. 2 . The thermal conductivity of graphite in longitudinal $\lambda_{p}$ and transverse $\lambda_{t}$ directions was assumed to be $30 \mathrm{~W} /(\mathrm{m} \cdot \mathrm{K})$.

The analysis of the data in Fig. 2 shows that when the nitrogen content in the sweep mixture grows from 10 to $100 \%$, the maximum corner temperature of the graphite block $t_{\text {ang }}$ increases by $5 \ldots 15^{\circ} \mathrm{C}$ depending on the value of the volumetric heat release in graphite $q_{v}$.

These figures are significantly different from the experimental data reported in [2], where the average coefficient of the effect of the mixture composition on graphite temperature is estimated in the range of $0.9 \ldots 1.2{ }^{\circ} \mathrm{C} / \%$. 


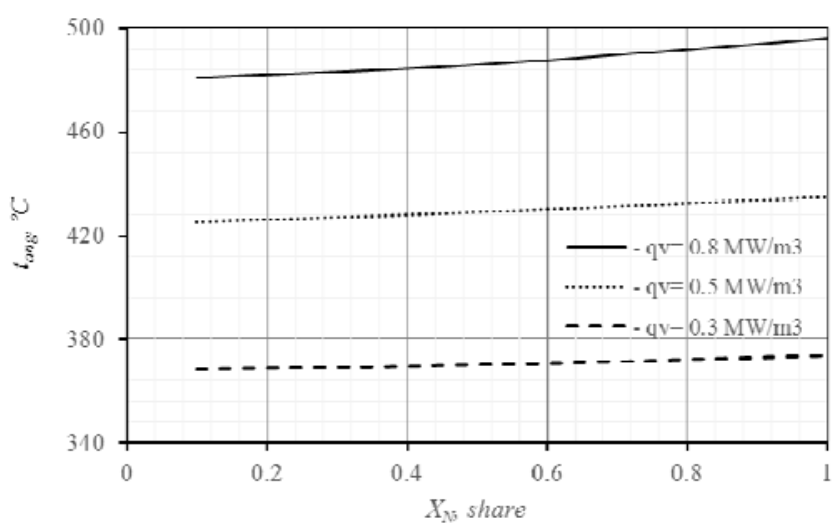

Fig. 2. Dependence of the maximum temperature of the graphite block (in the corner of graphite block) on the sweep mixture composition with no account taken of the contact thermal resistances.

It has been suggested that the reasons for this discrepancy can be unaccounted thermal resistances $R_{c i}$ at the junctions graphite block-outer ring, outer ring-inner ring, and inner ring-FC tube (Fig. 1).

In order to determine the source of discrepancies between the calculated and experimental data related to the graphite temperature, the technique described above has been verified through inclusion of the above-mentioned additional contact thermal resistances. To calculate the latter, the criterion equation from [7] was used

$$
\alpha_{k}=\frac{\lambda_{m i x} \cdot Y}{h_{0}}+8 \cdot 10^{3} \cdot \lambda_{e q} \cdot\left(\frac{P_{c n t}}{3 \cdot \sigma_{s t r}} \cdot K\right)^{0,86},
$$

where $\lambda_{\text {mix }}$ is thermal conductivity of the gas mixture; $Y=3.33$ is relative size of the gap; $\lambda_{e q}$ is equivalent thermal conductivity of the contact materials; $h_{0}$ is the total roughness of the contact surfaces; $K$ is the coefficient that depends on value $h_{0} ; P_{c n t}$ is contact pressure; $\sigma_{s t r}$ is tensile strength of the most plastic material among contact materials.

The improved technique was used to calculate the temperature of an individual graphite block by varying the composition of the sweep mixture $X_{N}$ and contact pressure $P_{\text {cnt }}$. The accepted graphite thermal conductivity $\lambda_{p}=\lambda_{t}=30 \mathrm{~W} /(\mathrm{m} \cdot \mathrm{K})$, and the volumetric heat release in graphite $q_{v}=0.55 \mathrm{MW} / \mathrm{m}^{3}$. The calculation results are plotted in Fig. 3 . 


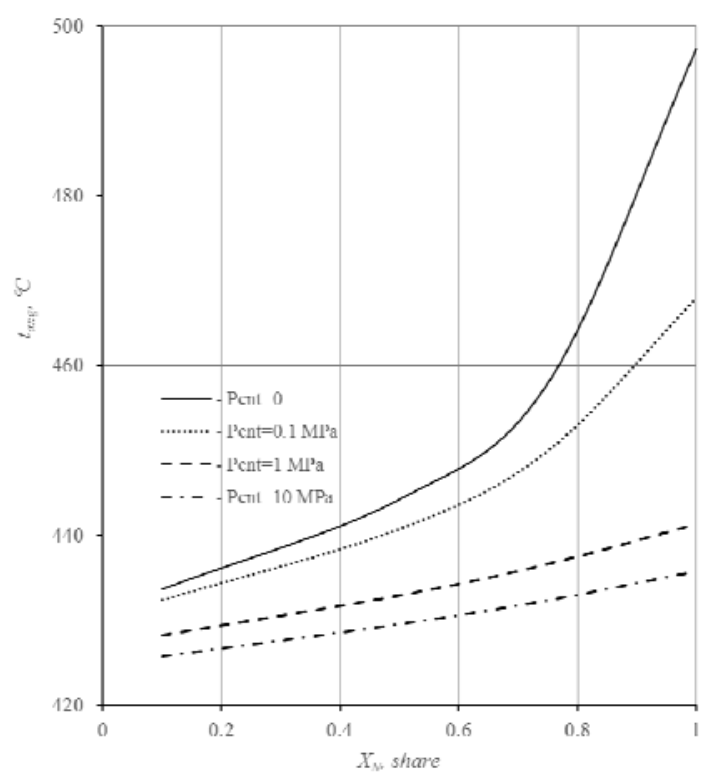

Fig. 3. Dependence of the maximum temperature of the graphite block (in the corner of the graphite block) on the sweep mixture composition at different values of contact pressure.

The analysis of the graphs in Fig. 3 and comparison with the data shown in Fig. 2 indicate that consideration of the contact thermal resistances significantly (1.07...1.15-fold) increases the specified temperature of the graphite moderator. The degree of the effect of the nitrogen content in the sweep mixture on the temperature level of the graphite moderator significantly (3...5-fold) increases as well.

\section{Conclusion}

An algorithm was updated and a program was developed for calculating the temperature of the graphite moderator in the RBMK reactor, which takes into account thermal resistances at the junctions of the elements of the graphite stack and FC.

This algorithm can significantly increase the precision of the engineering method for calculating the temperature of the graphite moderator of the RBMK reactor.

\section{References}

1. N.A. Dollezhal, Channel nuclear power reactor (Atomizdat, Moscow, 1980)

2. A.V. Vorobiev, A.M. Antonova, Proceedings of TPU 322, 182 (2013)

3. A.V. Vorobiev, A.M. Antonova, M.P. Vinogradov, EPJ Web Conf. 110, 01053 (2016)

4. A.M. Race, Thermal-hydraulic calculation of the reactor RBMK-1000 reactors: textbook (Izd. MEI, Moscow, 1982)

5. D.V. Gvozdyakov, A.O. Tanishev, S.A. Shvab, V.N. Martyshev, A.V. Kuzmin, MATEC Web Conf. 37, 01024 (2015)

6. M.A. Skachek, Thermal-hydraulic calculation of the RBMK-1000 reactor (Univ. MEI, 1982)

7. Y.P. Shlykov, E.A. Ganin, S.N. Tsarevsky, The thermal contact resistance (Energy, Moscow, 1977) 